\title{
Current Status of Laparoscopic Liver Resection: Experiences from Tertiary Center
}

\author{
Mohan Periyasamy, M.D. 1,2, Ho-Seong Han, M.D., Ph.D. ${ }^{1}$, Jai Young Cho, M.D., Ph.D. ${ }^{1}$, Yoo-Seok Yoon, M.D., Ph.D. ${ }^{1}$, \\ Young Rok Choi, M.D. ', Jae Seong Jang, M.D.', Seong Uk Kwon, M.D.', Sungho Kim, M.D. ', Jang Kyu Choi, M.D. ', \\ Hanisah Guro, M.D. ${ }^{1,3}$ \\ 'Department of Surgery, Seoul National University Bundang Hospital, Seongnam, Korea, ${ }^{2}$ Department of Surgery, Tamil Nadu Dr. MGR Medical University, \\ Chennai, India, ${ }^{3}$ Department of Surgery, Amai Pakpak Medical Center, Marawi, Philippines
}

\begin{abstract}
Laparoscopic liver resection has been widely accepted nowadays for selective cases of liver diseases. Laparoscopic left lateral sectionectomy and minor LLR are considered standard practice worldwide and cautious introduction of major laparoscopic liver resections like hemihepatectomies, central sectionectomy etc.. in institutions having experienced liver surgeons. Because of increasing young liver donor, laparoscopic donor hepatectomy is becoming popular, which gives better cosmetic outcomes. Many clinical trials compared laparoscopic liver resection safety, long term outcomes with open procedures. More recently, advances in laparoscopic instruments and techniques encouraged Korean surgeons to choose a laparoscopic procedure as one of the treatment options for benign or malignant diseases of liver.
\end{abstract}

Keywords: Laparoscopic liver resection (LLR), Hepatectomy, Sectionectomy, Segmentectomy, Intra hepatic duct (IHD) stones, HepatoCellular carcinoma (HCC), Laparoscopic donor hepatectomy
Received August 24, 2017

Accepted September 19, 2017

Corresponding author

Ho-Seong Han

Department of Surgery, Seoul

National University Bundang

Hospital, 166 Gumi-ro, Bundang-

gu, Seongnam 13620, Korea

Tel: +82-31-787-7091

Fax: +82-31-787-4055

E-mail: hanhs@snubh.org

Copyright $\odot 2017$ The Journal of Minimally Invasive Surgery. All rights reserved.

This is an Open Access article distributed under the terms of the Creative Commons Attribution Non-Commercial License (http:/ creativecommons.org/licenses/by-nc/4.0/) which permits unrestricted non-commercial use, distribution, and reproduction in any medium, provided the original work is properly cited.

\section{INTRODUCTION}

Since the first laparoscopic wedge resection of liver started in 1991, an increasing number of reports have demonstrated the safety, feasibility of laparoscopic liver resections. ${ }^{1}$ After the introduction of laparoscopic liver resection (LLR) in all over the world, there has been an exponential growth in the number of laparoscopic liver resection in korea., ${ }^{2,3}$ However, laparoscopic liver resection is still performed only at limited institutions. ${ }^{4}$ Although laparoscopic liver resection has several limitations, many of these are slowly being overcome because of advancement in instruments, imaging, surgical techniques and surgeons experience. ${ }^{4}$ So the aim of this study is to share our Seoul National University Bundang Hospital (SNUBH) institution experiences ${ }^{5}$ in laparoscopic liver resection for both benign and malignant diseases.

We started our laparoscopic liver resection service at SNUBH in 2003, initially we started with benign cases like unroofing of liver cyst, partial resection of liver then proceeded gradually to anatomical resection including major laparoscopic liver resection like hemihepatectomies, Sectionectomies, laparoscopic donor hepatectomy ${ }^{5-9}$ and surgery for choledochal cyst type $4 \mathrm{~A}^{10,11}$ At that time we were able to do most of the cases by total laparoscopic liver resection as the standard approach. ${ }^{12}$

At the oncological point of view, anatomical resection is better and safety for all malignant diseases and was recommended too, ${ }^{1,12,13}$ because of reduced intraoperative blood loss, 
safety resection margin and improving the survival rate by completely resecting the tumor bearing portal pedicles with limited parenchymal resection. ${ }^{14,15}$ So this can be achievable in cirrhotic liver also, as most of the hepatocellular carcinoma arises from cirrhotic liver. ${ }^{4,6,7,16,17}$ Other specific benefits of laparoscopic liver resection in cirrhotic patients include preservation of collateral veins, resulting in a reduced frequency of portal hypertension; decrease in the morbidity and manipulation of the liver, minimal insensible fluid loss and reduced risk of postoperative accumulation of ascites. ${ }^{18,19}$

The information in this review was extracted from literature search of medline.

\section{PREOPERATIVE DETAILS}

To determine the extent of resection all patients with liver disease were evaluated by preoperative examinations assessing liver function reserve [liver function test, Child-Pugh classification, and indocyanine green retention rate at 15 min (ICGR15)] and radiological studies[ultrasonography (US), biphasic computed tomography (CT), scans using a 16-channel multidetector row helical scanner, and contrast enhanced magnetic resonance (MR) imaging]. ${ }^{12,20}$ Intraoperative US was also performed. ${ }^{20,21}$ These preoperative and intraoperative radiological examinations delineated the location, size of the lesion and multiplicity of the tumors, and their anatomical relation with the major vascular structures. ${ }^{4}$

Laparoscopic liver resection was applied as a totally laparoscopic procedure. The nomenclature from the Brisbane 2000 guidelines for liver anatomy and resection was used to describe the extent of the hepatic resection. ${ }^{21,22}$ Nonanatomical liver resection involving removal of less than two segments was usually performed for patients with severe cirrhosis or peripherally located tumors. Major liver resection was considered when tumor was deeply located and remaining liver function was expected to be adequate. ${ }^{8}$ We mostly try to do anatomical resection of liver, because the preservation of hepatic functional reserve may have long term benefits by allowing free use of effective treatments in the event of recurrence. ${ }^{23}$

Written, informed consent was obtained from all patients prior to surgery, and the operative procedure was approved by the institutional ethical committee at our hospital.

\section{SURGICAL TECHNIQUES}

The perceived difficulty of surgical technique is quite subjective, so we slightly altered the existing technique and it was individualized. ${ }^{24,25}$ The operative techniques for laparoscopic liver resections in our institution have been described elsewhere. ${ }^{8,17}$ A pneumoperitoneum was established through a 10 $\mathrm{mm}$ umbilical port and maintained equal or below to $12 \mathrm{~mm}$ $\mathrm{Hg}$. We use four to five ports as standard with two $10 \mathrm{~mm}$ and three $5 \mathrm{~mm}$ port. A 30 degree laparoscope or flexible laparoscope was used. Laparoscopic ultrasonography was used for precise localization of the tumor, for demonstration of any satellite nodule of HCC, and for demarcation of an adequate tumor free margin. ${ }^{7,12,16}$ With the help of anaesthetists, sometimes we operate at low central venous pressure for bloodless field.

The superficial hepatic parenchyma was transected using the Harmonic Scalpel (Ethicon, Cincinnati, OH, USA) or rarely the SonoSurg (Olympus, Tokyo, Japan), and the deeper portion of the parenchyma was dissected using a laparoscopic cavitron ultrasonic surgical aspirator (CUSA). Once the specimen was completely detached, it was inserted into a protective bag. We usually extract the specimen through the incision created by extending the epigastric port site for the small specimens. For young women or large hepatectomy or in case of live donor hepatectomy, the specimen was removed through an additional suprapubic transverse incision. After careful hemostasis, a fibrin glue sealant (Greenplast; Green Cross Corp., Seoul, Korea) was applied to the raw surface. The surgical field then was irrigated, after which a silastic drain was inserted, and the wound was closed in layers. ${ }^{26}$

For major liver resection in the right side of the liver, including a hemihepatectomy and a right posterior sectionectomy, the liver was fully mobilized from the inferior vena cava, and multiple small hepatic veins were clipped and divided. Glisson's approach was used for anatomic major liver resection. No prior inflow (pringle maneuver) or outflow control was used for minor or non- anatomical resection. If pringle's used in major resection, we followed the principle of intermittent occlusion for 15 minutes with a gap of minimum 10 minutes between two occlusions in normal liver for a maximum of 45 minutes but for cirrhotic liver we rarely use pringle method, if at all used also just for some minutes depend upon the patients Child-Pugh class with a maximum of 30 minutes in toto.

After cholecystectomy, hilar dissection was performed to free the right and left Glisson' pedicles at the inferior surface of the quadrate lobe. Especially for a right posterior sectionectomy, the right Glisson's pedicle was further dissected in to the anterior and posterior Glisson's pedicles. The right Glisson's pedicle for a right hemihepatectomy or the right posterior Glisson's pedicle for a right posterior sectionectomy was extraparenchymally isolated and divide en masse using a linear stapler. ${ }^{8}$

In case of Intrahepatic duct stones(IHD), we follow the above procedure for stones with impaction, severe stricture (Grade 2, 3) and/or parenchymal atrophy. Otherwise we do 
laparoscopic IHD explorations. ${ }^{27,28}$

In the setting of lesions in segment 7 or 8, we inserted intercostal ports at $7^{\text {th }}$ or $9^{\text {th }}$ ICS respectively. ${ }^{29}$ If there is large cavities at the end of procedure, if possible we fill it with omentum in order to prevent the fluid collection and bowel adhesion there. ${ }^{30}$

\section{POSTOPERATIVE DETAILS}

After operation, all patients were followed at $3 \sim$ or $\sim 6$ months intervals. Follow up examinations included clinical examination, liver function tests, alpha-fetoprotein (AFP) level, and abdominal US or CT/MRI scans according to the necessity and cholangiography in patients treated for IHD stones.

\section{INDICATIONS}

The indications for laparoscopic liver resection includes benign tumor, liver abscess, intrahepatic duct stones, hepatocellular carcinoma (HCC), cholangiocellular carcinoma, mucinous carcinoma and metastatic tumor. The majority of the malignant lesions were HCC and metastatic tumor mainly from bowel cancer. ${ }^{3}$

The indications for performing laparoscopic liver resection for benign liver tumors included the presence of symptoms, danger of rupture, and uncertainity of diagnosis. For patients with hepatic cyst has undergone major hepatectomy, if they are suspicious of, or having malignant features like mural nodules, an intracystic septum or a honeycomb appearance. ${ }^{30}$

For the patients with HCC, the absence of severe portal hypertension and an adequate hepatic reserve were the prerquisites for surgery. For metastatic liver tumors from colorectal cancer, a liver resection was indicated when there was no evidence of extrahepatic disease. A simultaneous laparoscopic resection of metastatic liver tumor and a colorectal carcinoma was also a good indication of whether a curative resection was possible.

For the patients with IHD stones, the indications for a liver resection were the presence of IHD stricture, atrophy of the diseased liver parenchyma, or both. Anatomic liver resection and intraoperative choledochoscopic exploration of an IHD of the remnant liver were performed for the patients with IHD stone.

\section{EXTENDED INDICATIONS}

Due to improved laparoscopic instruments and increasing experience with laparoscopic and liver surgery in our institution we extended the indications by including multiple ma- lignant tumors, ${ }^{31}$ tumors larger then $5 \mathrm{~cm},{ }^{32}$ centrally located tumors associated closely with hilum, major hepatic veins or inferior vena cava, ${ }^{33}$ tumors located in posterosuperior segments, patients with previous upper abdominal surgery, right sided IHD stones, Type 4a choledochal cyst, laparoscopic donor hepatectomy.

\section{CONCLUSION}

The acceptance of laparoscopic liver resection both by surgeons and patients are increasing worldwide. Because of increasing experience of surgeons, the indications for LLR can also be extended as mentioned above. In addition anatomic resection is also feasible by LLR nowadays. Therefore, the extension of laparoscopic resection in liver diseases are going high and soon to be accomplished like in other fields.

\section{REFERENCES}

1) Guro H, Cho JY, Han HS, Yoon YS, Choi Y, Periyasamy M. Current status of laparoscopic liver resection for hepatocellular carcinoma. Clin Mol Hepatol 2016;22:212-218.

2) Han HS, Yoon YS, Cho JY, Hwang DW. Laparoscopic liver resection for hepatocellular carcinoma: korean experiences. Liver Cancer 2013;2:25-30.

3) Park JS, Han HS, Hwang DW, et al. Current status of laparoscopic liver resection in Korea. J Korean Med Sci 2012;27:767-771.

4) Hwang DW, Han HS, Yoon YS, Cho JY, Kim JH, Kwon Y. Totally anatomic laparoscopic right anterior sectionectomy. J Laparoendosc Adv Surg Tech A 2012;22:913-916.

5) Min SK, Han HS, Kim SW, Park YH, Lee HO, Lee JH. Initial experiences with laparoscopy-assisted and total laparoscopy for anatomical liver resection: a preliminary study. J Korean Med Sci 2006;21:69-74.

6) Yoon YS, Han HS, Choi YS, et al. Total laparoscopic left lateral sectionectomy performed in a child with benign liver mass. J Pediatr Surg 2006;41:e25-28.

7) Cho JY, Han HS, Yoon YS, Shin SH. Feasibility of laparoscopic liver resection for tumors located in the posterosuperior segments of the liver, with a special reference to overcoming current limitations on tumor location. Surgery 2008;144:32-38.

8) Cho JY, Han HS, Yoon YS, Shin SH. Experiences of laparoscopic liver resection including lesions in the posterosuperior segments of the liver. Surg Endosc 2008;22:2344-2349.

9) Suh KS, Yi NJ, Kim T, et al. Laparoscopy-assisted donor right hepatectomy using a hand port system preserving the middle hepatic vein branches. World J Surg 2009;33:526-533.

10) Shin SH, Han HS, Yoon YS, et al. Laparoscopically assisted extrahepatic cyst excision and left hemihepatectomy for a type IV-A choledochal cyst. J Laparoendosc Adv Surg Tech A 2008;18:831- 
835.

11) Jang JY, Yoon YS, Kang MJ, et al. Laparoscopic excision of a choledochal cyst in 82 consecutive patients. Surg Endosc 2013;27:1648-1652.

12) Yoon YS, Han HS, Cho JY, Ahn KS. Total laparoscopic liver resection for hepatocellular carcinoma located in all segments of the liver. Surg Endosc 2010;24:1630-1637.

13) Kim YK, Han HS, Yoon YS, Cho JY, Lee W. Total anatomical laparoscopic liver resection of segment 4 (S4), extended S4, and subsegments S4a and S4b for hepatocellular carcinoma. J Laparoendosc Adv Surg Tech A 2015;25:375-379.

14) Kawaguchi $Y$, Hasegawa K, Wakabayashi G, et al. Survey results on daily practice in open and laparoscopic liver resections from 27 centers participating in the second International Consensus Conference. J Hepatobiliary Pancreat Sci 2016;23:283-288.

15) Lee W, Han HS, Yoon YS, et al. Comparison of laparoscopic liver resection for hepatocellular carcinoma located in the posterosuperior segments or anterolateral segments: A case-matched analysis. Surgery 2016;160:1219-1226.

16) Yoon YS, Han HS, Choi YS, et al. Total laparoscopic right posterior sectionectomy for hepatocellular carcinoma. J Laparoendosc Adv Surg Tech A 2006;16:274-277.

17) Han HS, Yoon YS, Cho JY, Ahn KS. Laparoscopic right hemihepatectomy for hepatocellular carcinoma. Ann Surg Oncol 2010;17:2090-2091.

18) Hwang DW, Han HS, Yoon YS, et al. Laparoscopic major liver resection in Korea: a multicenter study. J Hepatobiliary Pancreat Sci 2013;20:125-130.

19) Brytska N, Han HS, Shehta A, Yoon YS, Cho JY, Choi Y. Laparoscopic liver resection for hepatitis $\mathrm{B}$ and $\mathrm{C}$ virus-related hepatocellular carcinoma in patients with Child B or $\mathrm{C}$ cirrhosis. Hepatobiliary Surg Nutr 2015;4:373-378.

20) Ahn KS, Han HS, Yoon YS, Cho JY. Laparoscopic anatomic S4 segmentectomy for hepatocellular carcinoma. Surg Laparosc Endosc Percutan Tech 2011;21:e183-186.

21) Ahn KS, Han HS, Yoon YS, Cho JY, Kim JH. Laparoscopic anatomical S5 segmentectomy by the Glissonian approach. J Laparoendosc Adv Surg Tech A 2011;21:345-348.

22) Ahn KS, Han HS, Yoon YS, Cho JY, Kim JH. Laparoscopic liver resection in patients with a history of upper abdominal surgery. World J Surg 2011;35:1333-1339.
23) Cho JY, Han HS, Yoon YS, Choi Y, Lee W. Outcomes of laparoscopic right posterior sectionectomy in patients with hepatocellular carcinoma in the era of laparoscopic surgery. Surgery 2015; 158:135-141.

24) Im C, Cho JY, Han HS, et al. Validation of difficulty scoring system for laparoscopic liver resection in patients who underwent laparoscopic left lateral sectionectomy. Surg Endosc 2017;31:430436.

25) Muangkaew P, Cho JY, Han HS, et al. Defining Surgical Difficulty According to the Perceived Complexity of Liver Resection: Validation of a Complexity Classification in Patients with Hepatocellular Carcinoma. Ann Surg Oncol 2016;23:2602-2609.

26) Cho JY, Han HS, Yoon YS, Shin SH. Outcomes of laparoscopic liver resection for lesions located in the right side of the liver. Arch Surg 2009;144:25-29.

27) Yoon YS, Han HS, Shin SH, Cho JY, Min SK, Lee HK. Laparoscopic treatment for intrahepatic duct stones in the era of laparoscopy: laparoscopic intrahepatic duct exploration and laparoscopic hepatectomy. Ann Surg 2009;249:286-291.

28) Kim YK, Han HS, Yoon YS, Cho JY, Lee W. Laparoscopic approach for right-sided intrahepatic duct stones: a comparative study of laparoscopic versus open treatment. World J Surg 2015;39:1224-1230.

29) Lee W, Han HS, Yoon YS, Cho JY, Choi Y, Shin HK. Role of intercostal trocars on laparoscopic liver resection for tumors in segments 7 and 8. J Hepatobiliary Pancreat Sci 2014;21:E65-68.

30) Lee DH, Cho JY, Han HS, et al. Laparoscopic treatment of hepatic cysts located in the posterosuperior segments of the liver. Ann Surg Treat Res 2014;86:232-236.

31) Yoon YS, Han HS, Cho JY, Yoon CJ, Kim JH. Laparoscopic approach for treatment of multiple hepatocellular carcinomas. Surg Endosc 2012;26:3133-3140.

32) Kwon Y, Han HS, Yoon YS, Cho JY. Are large hepatocellular carcinomas still a contraindication for laparoscopic liver resection? J Laparoendosc Adv Surg Tech A 2015;25:98-102.

33) Yoon YS, Han HS, Cho JY, Kim JH, Kwon Y. Laparoscopic liver resection for centrally located tumors close to the hilum, major hepatic veins, or inferior vena cava. Surgery 2013;153:502-509.

34) Han HS, Cho JY, Yoon YS, et al. Total laparoscopic living donor right hepatectomy. Surg Endosc 2015;29:184. 